\title{
Mitteilungen der ÖGKJ
}

Monatsschr Kinderheilkd 2015 • 163:1057-1057

DOI 10.1007/s00112-015-3426-4

(C) Springer-Verlag Berlin Heidelberg 2015

\section{Redaktion}

Prof. Dr. R. Kerbl, Leoben

Geschäftsstelle der ÖGKJ für Öffentlichkeitsarbeit und Standesführung

Ralph Kerschbaumer

c/o S12! studio12 gmbh

Kaiser Josef Straße 9, A-6020 Innsbruck

Tel.: +43512 890438 · Fax: + 43 512-890438-15

E-Mail: office@studio12.co.at·Internet:www.docs4you.at

\section{Geburtstage}

Die Österreichische Gesellschaft für Kinder- und Jugendheilkunde gratuliert herzlich ihren Mitgliedern, die im nächsten Monat einen „besonderen“ Geburtstag feiern:

\section{Jahre und älter werden:}

06.10.1925 | OMR Dr. Otto Donke, Linz

05.10.1926 | Dr. Erika Karalis, Wien

04.10.1927 | Hofrat Dr. H. Rode, Wien

\section{Jahre wird:}

06.10.1940 | Dr. Jörg Schriever, Mechernich (D)

\section{Jahre wird:}

22.10.1955 | Dr. Siegfried Kerbler, Wildon 